\title{
Risco privado em infra-estrutura pública: uma análise quantitativa de risco como ferramenta de modelagem de contratos*
}

\author{
Luiz E. T. Brandão** \\ Eduardo C. G. Saraiva***
}

SUMÁrio: 1. Introdução; 2. Risco privado em infra-estrutura pública; 3. Modelagem e análise de risco; 4. Aplicação; 5. Conclusões.

SuMMARY: 1. Introduction; 2. Private risk in public infrastructure; 3. Risk modeling and analysis; 4. Application; 5. Conclusions.

Palavras-chave: PPP; análise de projetos; opções reais; alocação de risco.

KEY WORDS: PPP; project analysis; real options; risk allocation.

Parcerias público-privadas (PPP) são arranjos contratuais onde o governo assume compromissos futuros por meio de garantias e opções. São alternativas para aumentar a eficiência do Estado por uma alocação mais eficiente de incentivos e riscos. No entanto, a determinação do nível ótimo de garantias e a própria alocação de riscos são geralmente realizadas de forma subjetiva, podendo levar o governo a ter que assumir passivos significativos. Este artigo propõe um modelo de valoração quantitativa de garantias

\footnotetext{
* Artigo recebido em fev. 2006 e aceito em jan. 2007. Os autores agradecem ao Centro de Excelência em Engenharia de Transportes (Centran), representado pelo seu diretor, coronel Paulo Roberto Dias Morales, pelos pesquisadores Alfredo Coary Iracema Gomes e Marco Túlio Peixoto Pimenta, pelo apoio técnico, pelos dados necessários à parte quantitativa do trabalho e pela disponibilidade de realizar novos cenários solicitados; aos engenheiros Renato Araújo de Freitas Gago, Sergio Bittencourt Varella Gomes e Luis Henrique Rosati Rocha, do BNDES, pela colaboração técnica no referencial teórico; a Marco Antonio Dias e Mateen Thobani pelos comentários e sugestões; e às Centrais Elétricas do Pará S.A. (Celpa) e Centrais Elétricas MatoGrossenses S.A. (Cemat) pelo apoio para a realização deste artigo.

** Professor do IAG/PUC-Rio. Endereço: Rua Marquês de São Vicente, 225 — Gávea - CEP 22453-900, Rio de Janeiro, RJ, Brasil. E-mail: brandao@iag.puc-rio.br.

$* * *$ Doutorando da EPGE/FGV, funcionário do BNDES. Endereço: Praia de Botafogo, 190, 11은 andar - CEP 22250-900, Rio de Janeiro, RJ, Brasil. E-mail: eduardo@fgvmail.br/ eduardo.saraiva@bndes.gov.br.
} 
governamentais em projetos de PPP por meio da metodologia das opções reais, e este modelo é aplicado a um projeto de concessão rodoviária. Os autores analisam o impacto de diversos níveis de garantia de receita sobre o valor e risco do projeto, bem como o valor esperado do desembolso futuro do governo em cada uma das situações, concluindo que é possível ao poder público determinar o nível ótimo de garantia em função do grau de redução de risco desejado, e que o desenho e a modelagem contratual de projetos de PPP podem se beneficiar de ferramentas quantitativas aqui apresentadas.

Private risk in public infrastructure: a quantitative risk analysis as a contract modeling tool

Public private partnerships (PPP) are contractual arrangements in which the government assumes future obligations by providing project guarantees. They are considered a way of increasing government efficiency through a more efficient allocation of risks and incentives. On the other hand, the assessment and determination the optimal level of these guarantees is usually subjective, exposing the government to potentially high future liabilities. This article proposes a quantitative model for the evaluation of government guarantees in PPP projects under the real options approach, and applies this model to a toll highway concession with a minimum revenue guarantee. It studies the impact of different guarantee levels on the value and the risk of the project, as well as the expected level of future cash payments to be made by the government in each case. It concludes that it is possible for the government to determine the optimal level of guarantees as a function of the desired level of risk reduction, and that the design and modeling of PPP contracts can benefit from the use of quantitative modeling tools such as the one presented here.

\section{Introdução}

A partir da década de 1990, observou-se em todo o mundo uma tendência clara para o aumento da participação da iniciativa privada em projetos de infra-estrutura pública, em substituição ao investimento governamental. A principal motivação para isso nos países desenvolvidos tem sido os ganhos de eficiência advindos da substituição da administração pública por empresas privadas e uma melhor alocação de riscos. Já nos países em desenvolvimento, além da falta de eficiência por parte do poder público para oferecer serviços de infra-estrutura a um nível adequado de qualidade, a motivação primordial foi: restrições de natureza orçamentária, incluindo a redução do ônus fiscal para o 
governo; e o acesso a capital para investimento. ${ }^{1}$ De 1990 a 2003, os países em desenvolvimento geraram um total de US\$ 410 bilhões em receitas de privatização, sendo a metade desse valor na América Latina. Destes, o Brasil foi o país que mais gerou recursos de privatização na década de 1990, respondendo por $22 \%$ do total. De 2000 a 2003 o maior volume de privatizações ocorreu na China, ficando o Brasil em segundo lugar, com 16\% do total.

\section{Figura 1}

\section{Evolução do volume de privatizações}

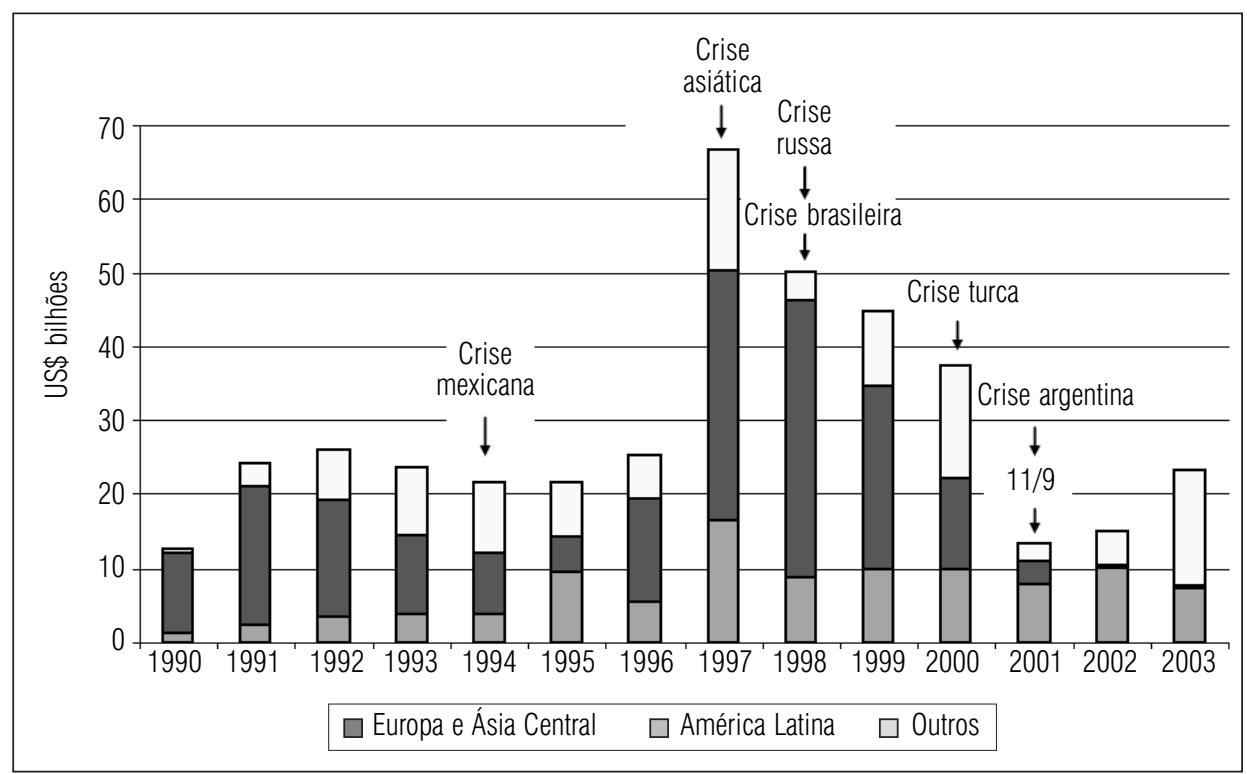

Fonte: Kekeri e Kolo, 2005.

Projetos de infra-estrutura possuem algumas características próprias que os diferenciam de projetos de investimento tradicionais, como o grande volume de investimentos exigido, longo prazo de maturação e o fato de cobrirem serviços considerados essenciais para a sociedade. Essas características fazem com que esses projetos sejam fortemente afetados por considerações políticas e regulatórias, que aumentam significativamente o risco deste investimento

\footnotetext{
${ }^{1}$ Kekeri e Kolo (2005) estimam que a produtividade das empresas públicas seja de duas a três vezes menor do que a do setor privado em alguns desses países.
} 
para o investidor privado. Em função disso, o investimento privado fará o necessário ajuste ao risco, mas veremos que a forma deste ajuste dependerá do tipo de privatização envolvido.

A privatização de infra-estrutura geralmente começa pela venda de empresas estatais, por meio da transferência de ativos públicos para empresas privadas, como ocorreu na Inglaterra na década de 1980, durante a administração de Margaret Thatcher e nos países em desenvolvimento na década de 1990. Na América Latina, esse processo envolveu principalmente os setores de energia, telecomunicações e saneamento. No Brasil, os setores de siderurgia, mineração, transportes e bancário também foram fortemente afetados. Por outro lado, esse processo tende a perder velocidade à proporção que o estoque de ativos privatizáveis do Estado diminui, sendo essa uma das principais causas da redução do volume de privatizações, observada a partir de 1997, conforme ilustrado na figura 1.

Uma vez esgotado o modelo de venda de ativos, restam os investimentos em novos projetos (projetos greenfield), que possuem peculiaridades distintas da simples venda de ativos do Estado. Nas privatizações que envolvem a venda de ativos, o ajuste para esses riscos se dá pela redução no preço de venda dos ativos, uma vez que um maior risco exigirá um maior retorno. Para novos projetos, no entanto, não é possível reduzir ainda mais o custo do investimento necessário, sob o risco de inviabilizar a implantação do projeto. Nesses casos, para se proteger, o investidor privado requer do governo garantias ou apoios que mitiguem os riscos e tornem o governo sócio do empreendimento de alguma forma.

Garantias e apoios contratuais têm sido usados com freqüência em projetos de infra-estrutura privada. O Banco Mundial auxiliou o governo da Colômbia a estruturar a concessão do projeto da rodovia El Cortijo-El Vino, onde foram concedidas garantias de tráfego e de custo de construção. Na expansão da usina térmica de Barranquilla, a um custo de US\$ 755 milhões, o governo colombiano garantiu que a distribuidora de energia estatal honraria um contrato tipo take or pay (Beato, 1997; Lewis e Moody, 1998). A concessão da rodovia SantiagoValparaíso-Viña del Mar, em 1998, com 130 km e US\$ 400 milhões, oferecia uma garantia de tráfego mínimo a um custo para o concessionário (Engel, Fisher e Galetovic, 2000). A via expressa da Linha Amarela, no Rio de Janeiro, em 1994, também incluiu um aporte a fundo perdido de US\$ 112 milhões, para um valor total de projeto de US\$ 174 milhões (Dailami e Klein, 1997).

Economias como a brasileira apresentam, ainda, alto grau de incerteza para realização de investimentos. As empresas privadas preferem investir com um bom ambiente regulatório, agências reguladoras independentes e pouco politizadas, e um Poder Judiciário forte e atuante. No passado, a incerteza da 
economia brasileira podia ser reduzida ou até eliminada pela presença direta ou indireta do governo, pela atuação das suas empresas estatais, como compradoras da produção do projeto, garantindo a demanda, ou como fornecedoras, garantindo a oferta. Assim, a presença da empresa estatal funcionava como uma âncora de hedge para os principais riscos, eliminando grande parte da incerteza presente na economia brasileira. Devido a isso, com a conclusão do ciclo de privatizações, os grandes projetos passaram a enfrentar maior dificuldade de estruturação no Brasil.

A presença do governo como mitigador de risco pode ser condição necessária, na medida em que podem estar sob seu controle variáveis que afetam condicionantes importantes do projeto (taxa de juros, respeito a contratos, regulação), ou mesmo variáveis de mercado que o investidor privado julgue tão arriscadas a ponto de inviabilizar o investimento. Um exemplo disso foi a licitação, em 1998, da rodovia Costanera Norte, no Chile, uma estrada urbana de $30 \mathrm{~km}$ que liga a cidade de Santiago ao aeroporto, na qual o governo inicialmente se recusou a conceder garantias julgadas necessárias pelos investidores privados e, em conseqüência, não obteve qualquer proposta. Anos mais tarde, após a inclusão de uma garantia de tráfego mínimo, a concessão foi licitada com sucesso e aberta ao tráfego em 2005.

Ao conceder garantias a projetos de infra-estrutura privada, o governo assume um passivo contingencial que, na maioria das vezes, não é adequadamente contabilizado nas contas públicas, que pode se tornar extremamente oneroso para o governo se os riscos envolvidos não forem quantificados e analisados corretamente. Exemplos típicos desse problema foram as garantias cambiais do governo espanhol na década de 1970 e a falência das concessões de estradas no México, após a crise de 1994, que custaram US\$2,5 bilhões e US\$ 8,9 bilhões, respectivamente, aos cofres públicos daqueles países.

Uma vez que existem projetos que requerem que o governo conceda algum tipo de garantia para se tornarem viáveis, o problema subseqüente passa a ser a definição de um nível de garantia que viabilize o projeto sem onerar o governo e a sociedade em demasia, em benefício exclusivo do concessionário privado. Até recentemente não havia uma maneira de se quantificar o valor dessas garantias e, por isso, o nível das garantias geralmente era determinado apenas pelas análises subjetivas. A determinação do nível de garantia ótimo requer a realização de uma valoração quantitativa de risco, o que não é possível fazer pelos métodos tradicionais de análise de projeto, como o do fluxo de caixa descontado. Isso se deve ao fato de que essas garantias têm características de opções, que somente podem ser valoradas utilizando-se técnicas de valoração de opções de projeto, desenvolvidas nas últimas décadas a partir do trabalho pioneiro de Black e Scholes (1973). 
Por meio de uma análise quantitativa de risco, mostramos que é possível determinar o valor de eventuais garantias oferecidas, o seu impacto na redução de risco do projeto, e, ainda, o valor esperado dos desembolsos futuros do governo em função das garantias dadas. Com isso podemos modelar uma forma de licitação que incorpore o valor das garantias oferecidas na decisão de outorga, que visa maximizar o retorno para a sociedade.

A seguir, discutiremos a questão do risco privado em projetos de infraestrutura pública, suas vantagens e limitações e mostramos como a análise quantitativa de risco pode contribuir para otimizar os custos dessas garantias para a sociedade. Depois, apresentaremos uma metodologia para avaliação de riscos com base nos ativos contingenciais e ilustraremos com uma aplicação ao projeto da BR-163. A seguir, as conclusões.

\section{Risco privado em infra-estrutura pública}

Baseados na percepção de que o setor privado tem melhores incentivos para operar serviços de infra-estrutura com maior eficiência, nas últimas décadas muitos países se voltaram para o setor privado para financiar, construir e operar projetos em áreas que até então eram consideradas prerrogativas do governo, como energia, telecomunicações, transportes e saneamento. Nos países em desenvolvimento, a tal motivação soma-se a escassez de recursos orçamentários para financiar novos projetos de infra-estrutura ou mesmo para manter a qualidade operacional dos investimentos já realizados. No Brasil, os projetos de infra-estrutura onde o setor privado poderia assumir integralmente os riscos de construção e/ou de operação estão diminuindo com as iniciativas dos últimos governos em privatizar ou conceder projetos de infra-estrutura existente. Após a venda dos ativos no setor de siderurgia, mineração, telecomunicações e distribuição de energia, as próximas concessões contemplam em sua maioria projetos tipo greenfield ou de recuperação de infra-estrutura existente, cuja viabilidade ocorrerá somente após a sua recuperação e após o desenvolvimento do mercado relacionado ao projeto. No entanto, a natureza desses serviços faz com que os riscos sejam altos, e os investidores, então, solicitem garantias governamentais para viabilizar o investimento, principalmente dentro da nova possibilidade aberta pela Lei no 11.079/04 (PPP), que é mais flexível que a Lei no 8.987/95 (concessão).

As PPPs estão em uso, em vários países desenvolvidos, como uma opção dos governos para aumentar a eficiência global. Nesses países há a possibilidade de realizar o projeto com recursos orçamentários (licitando as obras ou os serviços) ou a alternativa de desenvolver uma PPP. Nesse caso, a decisão ótima é aquela que oferece os melhores resultados para o contribuinte e a sociedade. No 
Brasil, a motivação para a realização das PPPs tem sido principalmente a incapacidade fiscal do governo. Nas PPPs, no entanto, o comprometimento do governo se dá ao longo do tempo e, assim, há o risco de se assumir passivos futuros que não estão sendo quantificados e contabilizados. Embora não causem impacto no fluxo de caixa hoje, esses passivos podem significar um pesado ônus para a sociedade no futuro. Dessa forma, se o governo assume riscos que deveriam ser sustentados pelos investidores, pode estar reduzindo o incentivo para uma maior eficiência e incorrendo em significativas responsabilidades. Uma solução para diminuir esse risco é quantificar o valor das garantias oferecidas nas PPPs.

\section{Parceria público-privada (PPP)}

O termo parceria público-privada (PPP) é usado de diferentes maneiras, o que dificulta uma definição precisa. Podemos considerar que as parcerias públicoprivadas são arranjos contratuais, entre o governo e o setor privado, para a provisão de bens e serviços tradicionalmente providos pelo setor público. Outras definições mencionam a questão da divisão de prêmio e risco entre setor público e setor privado pois, para que haja o envolvimento voluntário do setor privado na realização de investimentos, há a necessidade do estabelecimento do prêmio. Na tentativa de prover mais e melhores serviços para os seus concidadãos em um ambiente de orçamentos limitados, os governos, em todas as partes do mundo, estão fazendo esforço para desenvolver inovações organizacionais para a provisão de serviços públicos.

Com o mundo globalizado, os países disputam investimentos privados, como os estados brasileiros já fazem há alguns anos. O estado da federação que aumentar a alíquota de imposto unilateralmente, de forma agressiva, arrisca-se a perder a atividade econômica para outra unidade da federação. Um exemplo disso ocorreu com a elevação do ICMS sobre querosene de aviação no aeroporto do Galeão no Rio de Janeiro, que era o hub da América do Sul para vôos internacionais. A premissa do governo do estado de que seria impossível às empresas de aviação se recusarem a abastecer as aeronaves no estado se mostrou incorreta, quando elas transferiram os seus vôos internacionais para São Paulo. O cenário globalizado impõe aos países diminuição da carga tributária para não perderem empresas ou arrecadação.

A insatisfação com os custos, associada com a produção ou prestação de serviços feita pelo próprio governo, levou à expansão do recurso ao setor privado para a produção de serviços e obras públicas. Se um determinado governo local tivesse que manter equipes de funcionários públicos para construir, reparar ou manter pontes, escolas, hospitais ou prisões e tivesse que possuir as 
máquinas e equipamentos necessários ao processo, com certeza, teria deseconomias de escala em relação a uma empresa de construção. Para a empresa essa tarefa é o seu core business e pode atender a vários governos em vários países sem precisar incorrer em riscos de ociosidade das suas máquinas e equipamentos. Embora as experiências do governo com contratação de obras sejam variadas, a evidência sugere que há uma redução de custo e/ou um nível superior de serviços relativo a se a provisão for pelo próprio governo. Dessa forma, pode-se dizer que as principais vantagens da PPP são:

- competição ex ante - a principal razão para o sucesso da contratação de obra na redução de custo está no processo competitivo existente na concorrência para a execução da obra. Há serviços onde o número de competidores é grande e obriga a empresa privada que queira disputar um leilão competitivo a apresentar baixo custo, qualidade superior e ser inovadora. O não-cumprimento do contrato impõe pesados ônus: rescisão do contrato, multas, prejuízo na reputação e perdas de futuros negócios com o setor público. Nada disso ocorre se a provisão for realizada pelo setor público;

- economia de escala e de aprendizagem - Williamson (1979) aponta que a escolha de provisão externa de bens e serviços traz vantagens quando há significativos ganhos de economias de escala e de aprendizagem que não podem ser encontrados internamente no comprador (governo);

- ineficiência ex post - a situação de concessão, privatização ou PPP pode ser caracterizada como um investimento específico e os contratos de longo prazo podem ser incompletos. Williamson (1975, 1979, 1985) e Klein, Crawford e Alchian (1978) argumentam que, em função da sua natureza incompleta, os contratos podem ser revistos e renegociados com o tempo e o problema de ineficiência ex post não pode ser facilmente mitigado. Croker e Masten (1996) fazem uma comparação entre contratos de longo prazo e integração vertical. Concluem que o governo deve procurar o mercado spot sempre que for adquirir um serviço público onde não há a caracterização de investimento específico. Se há, o governo estará diante de dois cenários. Se o ambiente onde o projeto vai se desenvolver não é complexo, ou não há mudanças incertas, o governo pode firmar contratos de longo prazo; porém, se há, deve partir para a integração vertical. Grossman e Hart (1986) e Hart e Moore (1990) abordam a importância do direito de propriedade. O direito de propriedade sobre um ativo confere um poder de barganha ex post para o seu detentor;

complementaridade de tarefas — as PPPs apresentam uma natureza particular porque o governo está comprando o serviço e não a obra e a operação 
separadas. A vantagem dessa característica é que, para a disputa do leilão, os agentes podem se valer de desenvolvimento tecnológico e técnicas de gestão mais avançadas, que permitem fornecer o serviço em termos da sua característica funcional e qualidade por um custo mais baixo. A empresa ganhadora ou o consócio teria o incentivo para minimizar, intertemporalmente, os custos totais para prover o serviço. Assim, poderia gastar mais no investimento inicial para reduzir o custo de operação e manutenção ao longo da operação. Diferentemente das "privatizações" onde o governo perde o controle sobre o serviço, nas PPPs o governo é parte do desenvolvimento do projeto e, para tanto, impõe-se um monitoramento e uma regulação maior;

v financiamento privado e o verdadeiro custo de capital — os defensores das PPPs identificam como uma das suas principais vantagens o financiamento privado de bens públicos. Intertemporalmente pode-se chegar a uma redução do custo de investimento ou do custo de operação (redução do ônus ao contribuinte) e ter, na prática, um menor custo de capital global;

v incentivos mais eficazes e alocação ótima de riscos. O setor privado é, geralmente, hábil para mais rapidamente realizar a introdução de produtos ou tecnologias inovadores e tem maior flexibilidade e pode premiar os funcionários por reduzirem os custos. Para a alocação ótima de riscos deve-se esperar que a gestão privada só permita assumir o risco com que pode arcar. A política ótima de estruturação de um projeto é aquela que aloca os riscos para a parte que tem melhor capacidade e incentivo para lidar com ele.

\section{Riscos privados e os novos projetos de infra-estrutura}

Projetos privados de infra-estrutura são sujeitos a regulação governamental, abrangem serviços considerados essenciais pela sociedade, exigem grandes investimentos irreversíveis que somente podem ser recuperados no longo prazo e são oferecidos de forma monopolista. Essa combinação de fatores faz com que, uma vez implantados, o interesse do poder público e o do investidor privado passem a divergir, e faz com que esses projetos fiquem sujeitos a pressões dos usuários e ações oportunistas do governo, o que aumenta substancialmente o risco do investidor. É necessário, portanto, um ajuste ao risco que permita ao investidor receber um retorno esperado que seja proporcional ao risco do investimento. Nos projetos de privatização que envolvem apenas a venda de ativos do Estado, como no caso das empresas estatais no Brasil, nos setores de siderurgia, mineração, transportes, telecomunicações, energia etc., o ajuste ao risco se faz simplesmente pela redução nas ofertas 
de preço de compra desses ativos nos leilões de privatização. Deparado com um maior grau de incerteza, o investidor irá descontar os fluxos de caixa futuros a uma taxa maior, reduzindo o valor presente do ativo. Nesse caso, o ajuste é completo e nenhuma outra forma de compensação se faz necessária, o que explica o fato de que a concessão de garantias adicionais na grande maioria dos países onde ocorreu a privatização de empresas estatais e venda de ativos de governo é escassa.

Uma vez esgotado o estoque de ativos privatizáveis do Estado, observase que o ritmo de privatizações tende a diminuir, pois resta a privatização de projetos novos de concessão de infra-estrutura do tipo greenfield, de administração mais complexa. Se na venda de ativos o ajuste ao risco é feito no preço de venda, nos projetos novos essa flexibilidade não mais existe, pois supõe-se que o investimento exigido para a implantação do projeto já seja o mínimo necessário. Nesse caso, o ajuste ao risco deverá ser feito de outra forma e, para mitigar esses riscos, freqüentemente os investidores privados exigem alguma forma de garantia governamental que tenha o efeito de transferir uma parcela desses riscos para o poder público. Entre eles, Thobani (1999) destaca garantia do governo contra riscos de mudanças na política ou no clima regulatório, de quebra de contratos, de custos extras, baixa demanda ou flutuações na taxa de câmbio ou taxa de juros.

Para atrair investimentos privados em geração de energia, por exemplo, na década de 1990 o governo do Paquistão ofereceu uma garantia de compra da energia gerada a preço fixo. Para os investidores, no entanto, essa garantia era insuficiente, e o investimento somente foi realizado após o Banco Mundial dar uma contragarantia, por meio de um acordo onde quaisquer valores desembolsados pelo banco seriam transformados em dívida soberana daquele país junto ao Banco Mundial. Nos anos 1960 e 1970, quando a rede de auto-estradas espanhola começou a ser construída, o governo espanhol contava com uma escassez de moeda estrangeira e exigiu que os investidores se financiassem no mercado externo, oferecendo para isso garantias cambiais que cobriam 75\% desses empréstimos. Mais recentemente, na Colômbia, o governo colombiano concordou em reembolsar o concessionário, se o tráfego fosse menor que $90 \%$ de um nível predeterminado, garantindo assim uma receita mínima para o investidor quando da concessão de um contrato BOT (build, operate, transfer) para uma nova auto-estrada até o aeroporto de Bogotá.

Por outro lado, a concessão indiscriminada de garantias contratuais pode onerar em demasia o Estado, pois ao oferecer essas garantias o governo está criando um passivo e uma responsabilidade potencial para o futuro. Embora não produza impacto no caixa do governo no momento presente, esse compromisso pode significar um pesado ônus para as gerações futuras. No caso do 
Paquistão, as fortes garantias ofertadas fizeram com que houvesse um excesso de investimento em geração de energia no país, configurando uma alocação ineficiente de recursos escassos. No caso das auto-estradas espanholas, a desvalorização cambial que ocorreu nos anos seguintes acarretou um custo de US\$ 2,7 bilhões aos contribuintes. O caso mais oneroso foi o ocorrido no programa de concessões rodoviárias do México. Gómez-Ibáñez (1997) relata que, entre 1989 e 1995, o país construiu $5.120 \mathrm{~km}$ de vias expressas por meio de concessões privadas, o maior programa do mundo de privatização de rodovias na época. No entanto, erros de licitação, uma concessão inflexível, tráfego menor do que o esperado, garantias implícitas e uma severa crise cambial levaram o governo mexicano em agosto de 1997 a assumir o controle de 25 concessões a um custo de US\$ 8 bilhões para os cofres públicos.

Quando a rentabilidade do projeto for insuficiente ou o risco excessivo, o poder concedente pode oferecer vantagens e/ou garantias adicionais que tornem o projeto viável do ponto de vista do concessionário privado, na forma de flexibilidades ou opções contratuais. No entanto, o valor dessas opções raramente é levado em consideração ou incluído na análise de viabilidade econômica do projeto de forma apropriada devido às limitações das metodologias tradicionais. No caso das receitas ficarem muito abaixo das expectativas, por exemplo, o projeto recebe um subsídio governamental proporcional à redução na demanda esperada, de forma a manter o equilíbrio econômico financeiro do contrato. Outras opções também podem estar presentes, como a opção de estender (ou reduzir) o período da concessão ou o adiamento de pagamentos devidos ao poder concedente.

\section{Riscos e garantias em projetos de concessão rodoviária}

Os riscos associados a projetos de concessão rodoviária têm sido identificados, mas a sua modelagem é pouco discutida. Trabalhos realizados por Standard and Poor's $(2002,2003)$ concluíram que os modelos de projeção de tráfego geralmente oferecem resultados otimistas que não se verificam na prática, e que esses projetos tendem a ter uma performance abaixo das expectativas nos anos iniciais. Fishbein e Babbar (1996) relacionam os principais riscos a que uma concessionária responsável pelo financiamento, construção e operação do projeto está sujeita:

、 riscos pré-construção - aquisição e liberação da faixa de domínio, obtenção das licenças ambientais e de construção; 
- risco de construção - problemas técnicos e geológicos inesperados, alteração de projeto, atrasos e aumento de custos;

$\checkmark$ risco de demanda e receita - baixa demanda de mercado, baixo valor da tarifa;

v risco de câmbio - flutuação na taxa de câmbio, inconvertibilidade de moeda;

v risco de força maior - terremotos, enchentes, guerra;

v risco de responsabilidade civil — indenizações por acidentes;

v risco político - interrupção unilateral do projeto, não-cumprimento do contrato de concessão, aumento de impostos;

v risco financeiro - fluxo de caixa insuficiente para o pagamento dos juros da dívida ou dividendo aos acionistas.

O impacto de cada um dos riscos citados acima dependerá das características do projeto em análise. Grande parte do risco financeiro ocorre em função das incertezas a respeito das receitas geradas pelo mercado futuro, e devido às dificuldades de se estimar corretamente o mercado no futuro, o risco de demanda geralmente é considerado o principal risco de um projeto de concessão. O potencial para erros nessas estimativas pode ser ilustrado pelos resultados do projeto da rodovia M1, na Hungria, que nos primeiros seis meses de operação conseguiu atrair apenas metade do tráfego esperado. Nos Estados Unidos, a Dulles Greenway, na Virgínia do Norte, também registrou apenas $34 \%$ do nível de tráfego projetado no seu primeiro ano de operação.

Dado que uma parte significativa do fluxo de caixa de um projeto de concessão é redirecionada ao serviço da dívida, a estabilidade desses fluxos é de fundamental importância para a minimização do risco de crédito do projeto. Assim, uma das formas de viabilizar projetos é estabelecer garantias de receita que cubram pelo menos o serviço da dívida do projeto, reduzindo o seu risco de crédito.

De todos os mecanismos de garantia possíveis, as garantias de investimento, de financiamento e de risco cambial são as que expõem o governo ao maior risco. Na garantia de investimento, o governo dá ao concessionário a opção de vender a sua participação no projeto por um valor que lhe garante um retorno mínimo preestabelecido no seu investimento. Embora não haja custo para o governo no caso do projeto gerar retornos suficientes para o concessionário, nessa modalidade o governo assume todo o risco do projeto, e os incentivos para obter um bom desempenho no projeto por parte do conces- 
sionário se reduzem consideravelmente. A garantia direta de financiamento protege o credor contra qualquer deficiência de caixa do projeto, mas também apresenta um alto risco para o governo. A garantia cambial é relevante apenas em projetos onde a moeda de financiamento é diversa daquela em que as receitas são incorridas, mas a experiência mostra que ela também pode representar um passivo contingencial alto para o poder público. Outras formas de suporte, como recursos a fundo perdido e empréstimos subordinados, podem ser importantes para viabilizar um projeto e têm a vantagem de limitar os riscos do governo a um valor predeterminado.

Uma alternativa para o desembolso inicial é o pagamento do pedágiosombra e a garantia de tráfego ou receita mínima. Nessas modalidades, o custo para o governo é distribuído ao longo do período da concessão, ao invés de ser concentrado no seu início. No pedágio-sombra, o governo complementa o pedágio pago por cada veículo que trafega na estrada, por meio de um pagamento anual por veículo. O problema com essa garantia é que ela pode ser onerosa para o governo, se o volume de tráfego for alto; e insuficiente para garantir o retorno dos investidores, se o volume for baixo, resultando num aumento de risco do projeto, ao invés de uma redução.

A garantia de demanda mínima, por outro lado, é uma das formas mais comuns de apoio governamental. Nessa modalidade, o governo compensa o concessionário, se o nível de demanda ou a receita do projeto cair abaixo de um valor mínimo preestabelecido, sendo o nível de demanda mínima tipicamente estabelecido num patamar de $70 \%$ a $90 \%$ da demanda prevista. Da mesma forma, o governo pode também exigir uma contrapartida para o estabelecimento de um piso, na forma de um teto de demanda ou receita, acima do qual o concessionário repassa toda ou parte da receita excedente.

A extensão do prazo de concessão é uma das formas de garantia que menos oneram o setor público, mas, por outro lado, também não protege os investidores contra eventuais quedas de receita no curto prazo. O incremento de receitas se dá por meio de concessões governamentais que limitam a construção de vias alternativas que poderiam desviar o tráfego da rodovia concedida, construção de acessos ou estradas que possam alimentar o tráfego existente, e a autorização para utilizar a faixa de domínio para outras atividades de geração de receita. Essa garantia geralmente tem baixo custo para o governo e pouco impacto sobre a viabilidade econômica da concessão, dada a grande dificuldade em prever receitas futuras decorrentes dela. Na figura 2 podemos observar que entre as garantias mencionadas, quatro apresentam o melhor custo-benefício. 
Figura 2

\section{Alternativas de garantias governamentais}

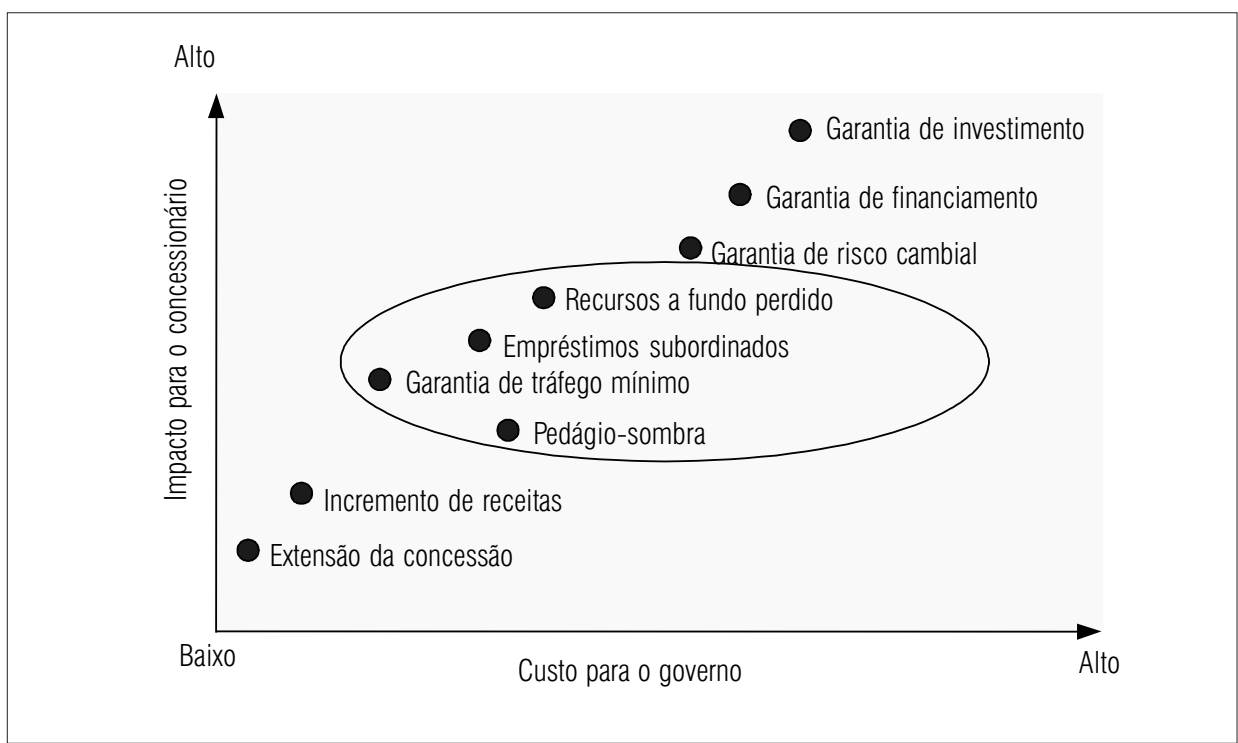

Fonte: Fishbein e Babbar, 1996.

\section{Modelagem e análise de risco}

A participação do poder público como garantidor de última instância de uma PPP faz com que ele tenha uma responsabilidade importante na implantação de projetos que possuam viabilidade técnica, mas não-econômica no modelo clássico de análise de uma concessão. Esse objetivo pode ser alcançado oferecendo-se garantias que limitam os prejuízos e reduzem o risco do concessionário, de forma a permitir a realização e a continuidade do projeto. $\mathrm{O}$ apoio do governo a contratos de PPP pode assumir diversas formas, desde a extensão do período contratual até uma garantia de um valor presente líquido para o projeto ou uma rentabilidade mínima para o capital investido, representando diferentes graus de mitigação de risco. Atualmente, a determinação do nível ótimo de tais modalidades de apoio é realizada de forma subjetiva, uma vez que a metodologia utilizada para a modelagem de projeto (VPL) não comporta a análise do impacto das flexibilidades que tais apoios oferecem ao concessionário. No caso brasileiro, onde o governo já chegou praticamente no limite de aumento da carga tributária, é imperativo haver a valoração dos custos dessas garantias. 
Quando o governo garante um nível mínimo de demanda, elimina a parcela mais desfavorável da distribuição dos retornos de um projeto. Esse fato produz dois efeitos financeiros distintos: por um lado, aumenta a média dos retornos; por outro, reduz o risco do projeto com a eliminação dos estados mais desfavoráveis. Reduzir o risco de um projeto significa reduzir a taxa de desconto, o que aumenta o valor do projeto. Mas o objetivo básico do apoio governamental é oferecer flexibilidade ao concessionário, visando à mitigação do risco do projeto de concessão. Assim, por definição, a própria existência desses fatores mitigadores irá alterar o risco do projeto a cada etapa da sua realização, tornando o cálculo da taxa de desconto apropriada para o projeto extremamente difícil. A única metodologia que permite determinar o valor de um programa de apoio governamental contingencial para a viabilização de um projeto de PPP é aquela que incorpora conceitos de valoração de opções na sua metodologia, também conhecida como método das opções reais. No método das opções reais, cada uma dessas distintas formas de apoio é modelada como opção de que o concessionário ou o próprio poder público dispõe, levando-se em consideração as incertezas do projeto, a irreversibilidade do investimento e as flexibilidades definidas contratualmente. Uma garantia de tráfego ou de receita, por exemplo, corresponde a uma opção de venda, ou um seguro, cujo valor pode ser calculado por meio do modelo de Black e Scholes, para os casos mais simples.

A literatura a respeito da valoração de ativos contingenciais em rodovias pedagiadas é limitada. Brandão (2002) apresenta uma modelagem da concessão da rodovia Presidente Dutra que incorpora o valor da opção de expansão, de abandono e os efeitos do risco político, e conclui que essas flexibilidades gerenciais aumentam substancialmente o valor do projeto em relação à modelagem tradicional. Ng e Björnsson (2004) apresentam argumentos a favor do uso da teoria das opções reais para a análise de um projeto de concessão rodoviária, em comparação com os métodos tradicionais de análise de decisão. Rose (1998) mostra que o valor do projeto da rodovia pedagiada de Melbourne na Austrália (Melbourne Central Toll Project) aumenta consideravelmente quando é incorporado na análise o valor das opções de acréscimo de receita disponíveis para a concessionária privada. Bowe e Lee (2004) analisam o projeto de transporte rápido por trilhos de Taiwan (Taiwan High-Speed Rail Project), onde o concessionário tem a opção de desenvolver projetos imobiliários ao longo da via e mostra que o valor dessas opções reduz significativamente o risco do projeto. No entanto, os modelos desenvolvidos para ambos os trabalhos não analisam o efeito de garantias governamentais sobre esses projetos. Charoenpornpattana e colaboradores (2002) avaliam dois tipos de subsí- 
dios governamentais: a garantia de preço mínimo e o pedágio-sombra como uma cesta de opções independentes, mas o seu modelo não considera diretamente as garantias de receita. Lewis e Mody (1997) e Irwin (2003) mencionam um estudo realizado pelo Banco Mundial para valorar as garantias de tráfego e receita oferecidas no projeto da concessão rodoviária El Cortijo-El Vino, na Colômbia, utilizando modelos de avaliação de opções. Neste artigo, propomos um modelo de valoração de garantias de tráfego mínimo para o concessionário e dos desembolsos esperados para o poder público.

\section{Modelagem das garantias}

Modelamos uma garantia de tráfego mínimo num projeto de concessão rodoviária com o objetivo de determinar o valor e o impacto de tal garantia na viabilidade econômica e financeira do projeto. Para tanto, consideramos uma garantia de tráfego onde o poder público se obriga a realizar um pagamento à concessionária cada vez que o tráfego na rodovia (TMDA - tráfego médio diário anual) cair abaixo de um piso mínimo preestabelecido durante um determinado período de tempo. Considerando uma tarifa de pedágio constante, essa garantia é equivalente a uma garantia de receita mínima.

Seja $R_{t}$ a receita observada do projeto $\left(R_{t}=T M D A_{t} \times\right.$ tarifa pedágio $)$ no ano $t$ e $H_{t}$ a receita mínima garantida pelo governo naquele mesmo ano. Nesse caso, considerando a garantia recebida, a receita efetiva da concessionária no ano $t$ será dada por:

$$
R(t)=\max \left(R_{t}, H_{t}\right)
$$

Da mesma forma, o valor $G(t)$ da garantia governamental concedida naquele ano será:

$$
G(t)=\max \left(0, H_{t}-R_{t}\right)
$$

Dada a incerteza a respeito dos níveis futuros de tráfego e receita, para a modelagem dessa variável ao longo de todo o período da concessão, consideramos que o tráfego e, por conseqüência, a receita variam estocasticamente no tempo, seguindo um movimento geométrico browniano (MGB), conforme é habitual na literatura. Essa modelagem implica que a receita (e o tráfego) nunca poderá ser negativa e que a sua volatilidade é constante no tempo, e é representada pela seguinte forma:

$$
d R_{1}=\alpha_{1} R_{1} d t+\sigma_{R} R_{1} d z
$$


onde:

$d R_{t}$ é a variação incremental da receita no intervalo curto de tempo $d t$;

$\alpha_{t}$ é a taxa de crescimento da receita no intervalo curto de tempo $d t$;

$\sigma_{R}$ é a volatilidade da receita;

$d z=\varepsilon \sqrt{d t}$, onde $\varepsilon \sim N(0,1)$ é um processo de Wiener padrão.

Esse processo pode ser completamente especificado, considerando-se apenas o seu valor inicial $R_{0}$, a taxa de crescimento em cada ano e a volatilidade do processo. A equação (2) representa o processo "verdadeiro" de evolução da receita do projeto. Para efeito de valoração das garantias, no entanto, é necessário utilizar o processo neutro a risco representado pela equação (3):

$$
d R_{t}=\left(\alpha_{t}-\lambda \sigma_{R}\right) R_{t} d t+\sigma_{R} R_{t} d z
$$

onde $\lambda \sigma_{R}$ é o prêmio de risco das receitas e $\lambda=\rho\left[\frac{E\left[R_{m}\right]-r}{\sigma_{m}}\right]$ e $\sigma_{R}$ são respectivamente o preço de mercado do risco e a volatilidade das receitas. ${ }^{2}$ Uma análise mais detalhada desse modelo pode ser encontrada em Hull (2003).

Dado que as receitas, ou mesmo o tráfego do projeto, não são um ativo de mercado, não é possível determinar diretamente qual o prêmio de risco apropriado para essa fonte de incerteza. Irwin (2003) sugere uma solução exógena, onde adota valores arbitrários para a determinação prêmio de risco das receitas. No entanto, é possível estimar esse valor a partir do processo dos fluxos de caixa e do valor do projeto. Como a única fonte de incerteza do projeto é a das receitas, a correlação entre as variações da receita e o mercado será idêntica à correlação dos retornos do projeto com o mercado, o que faz com que o parâmetro $\lambda$ seja uma constante. Assumindo a premissa de que o valor presente do projeto sem opções é uma estimativa confiável do seu valor de mercado, podemos determinar o prêmio de risco dos fluxos de caixa do

${ }^{2}$ Pelo CAPM o prêmio de risco das receitas é $\beta_{R}\left(E\left[R_{m}\right]-r\right)$, onde $\beta_{R}=\frac{\sigma_{m, R}}{\sigma_{m}^{2}}$. Substituindo o valor de $\beta$, multiplicando por $\left(\frac{\sigma_{R}}{\sigma_{R}}\right)$ e rearranjando obtemos $\underbrace{\left(\frac{\sigma_{m, R}}{\sigma_{m} \sigma_{R}}\right)}_{\rho}\left(\frac{E\left[R_{m}\right]-r}{\sigma_{m}}\right) \sigma_{R}=$ $\rho\left(\frac{E\left[R_{m}\right]-r}{\sigma_{m}}\right) \sigma_{R}=\lambda \sigma_{R}$. 
projeto pelo CAPM e o preço de mercado do risco das receitas $\lambda$ pode então ser determinado pela equação (4).

$$
\lambda=\frac{\beta_{c}\left(E\left[R_{m}\right]-r\right)}{\sigma_{c}}
$$

A volatilidade do processo das receitas pode ser observada pelas séries históricas de outras rodovias semelhantes. A volatilidade do projeto pode ser estimada por meio de uma simulação de Monte Carlo aplicada ao fluxo de caixa estocástico sem consideração das opções, conforme proposto por Copeland e Antikarov (2001) e adotando-se a modificação proposta por Brandão, Dyer e Hahn (2005), doravante $\mathrm{BDH}$. Devido ao efeito da alavancagem de custos, a volatilidade dos fluxos de caixa tende a ser maior do que a volatilidade das receitas, o que reduz significativamente o prêmio de risco das receitas, que é dado por:

$$
\lambda \sigma_{R}=\beta_{C}\left(E\left[R_{m}\right]-r\right) \frac{\sigma_{R}}{\sigma_{C}}
$$

Dado o processo neutro a risco das receitas definido em (3), o valor das opções de garantia é determinado simulando-se diferentes cenários futuros com um modelo de Monte Carlo, considerando-se a possibilidade de exercício da opção sempre que o valor da receita em um determinado ano for menor do que a receita mínima garantida. $\mathrm{O}$ valor esperado da opção é então descontado a valor presente pela taxa livre de risco. É importante notar que as opções de garantia são formadas por uma série de opções européias independentes, com prazos de maturidade variando entre um e 25 anos. Dessa forma, em princípio, o seu valor pode ser calculado diretamente pela equação de Black, Scholes e Merton. No caso, como a taxa de crescimento das receitas também é variável, optamos por valorar as opções por meio de simulação. Repetindo-se essa análise para cada um dos 25 anos da concessão, o valor da concessão com a garantia de receita é obtido simplesmente somando-se o valor presente de todas as 25 opções ao VPL estático do projeto.

\section{Aplicação}

Utilizando a metodologia proposta, analisamos a seguir a viabilidade e riscos da rodovia BR-163 no trecho Cuiabá-MT/Santarém-PA, com cerca de $1.600 \mathrm{~km}$ em pista simples. Consideramos a existência de uma garantia de tráfego e receita e adotamos os dados de tráfego e estimativas de custo do projeto que nos foram gentilmente fornecidos pelo Centran - Centro de Excelência em Engenharia de Transportes. 
Por se tratar de uma rodovia pioneira, os riscos de tráfego são significativos, dado que não há registro confiável do tráfego histórico na rodovia, nem existem estudos socioeconômicos consensuais que garantam um nível de tráfego futuro. Assim, como forma de mitigação de riscos por parte do governo, modelamos os efeitos sobre a concessão de uma garantia de tráfego mínimo, com o objetivo de determinar qual seria o nível ótimo dessa garantia e o seu custo para o governo. Essa garantia dá ao concessionário a opção de recorrer ao poder público para ser ressarcido de perdas de receita, toda vez que o tráfego observado na rodovia for menor do que um nível preestabelecido.

Consideramos como ano 0 da concessão o ano de 2007, e que a construção e pavimentação total da rodovia levarão cerca de três anos. Dessa forma, as primeiras receitas operacionais com pedágio estão previstas para o ano 2 , que corresponde ao ano de 2009. Não haverá cobrança de pedágio no ano 1 e, nos anos 2 e 3, a cobrança ocorrerá apenas em quatro praças de pedágio, representando $28 \%$ do fluxo total de veículos na rodovia nesses dois anos. A tarifa básica para o pedágio, adotada no presente trabalho, foi de $\mathrm{R} \$ 7,60$. $\mathrm{O}$ horizonte de estudo corresponde ao prazo contratual da concessão de 25 anos, portanto, o estudo tem início no ano 2007 (ano 0) e término no ano 2032 (ano 25). Foi assumido também um custo de capital próprio de $15 \%$ a.a. reais.

\section{Modelagem}

O anexo I mostra o fluxo de caixa estático da concessão. O investimento inicial é de R\$ 1.151,3 milhões distribuídos ao longo dos três primeiros anos, considerando-se um financiamento de 70\%, e a análise estática indica que VPL da concessão é de R \$ 384,1 milhões. Os resultados encontrados indicam a viabilidade financeira da concessão, visto que o VPL é positivo. Esse resultado, no entanto, não é suficiente para que o concessionário possa tomar sua decisão, pois não fornece uma indicação dos riscos envolvidos na implantação e operação do projeto, o que somente pode ser feito por meio de uma modelagem estocástica. Para tanto, foram considerados: uma volatilidade de tráfego de 6\% a.a. e um nível de tráfego inicial de 106.506 veículos, equivalentes diários referenciados ao ano de 2004 nas 13 praças de pedágio da rodovia e que estão sujeitos a um crescimento mais acentuado nos anos iniciais da concessão. A análise de risco do projeto realizada pela simulação de Monte Carlo, considerando agora a incerteza sobre o nível futuro de tráfego, indica que o VPL do projeto tem um desvio-padrão de $\mathrm{R} \$ 258,1$ milhões, conforme podemos observar na figura 3, o que indica que o projeto apresenta um risco alto. Essa análise não incorpora o valor e os impactos sobre o projeto de possíveis garantias que o governo pode oferecer para tornar o projeto mais atrativo. 
Figura 3

Distribuição do VPL da concessão

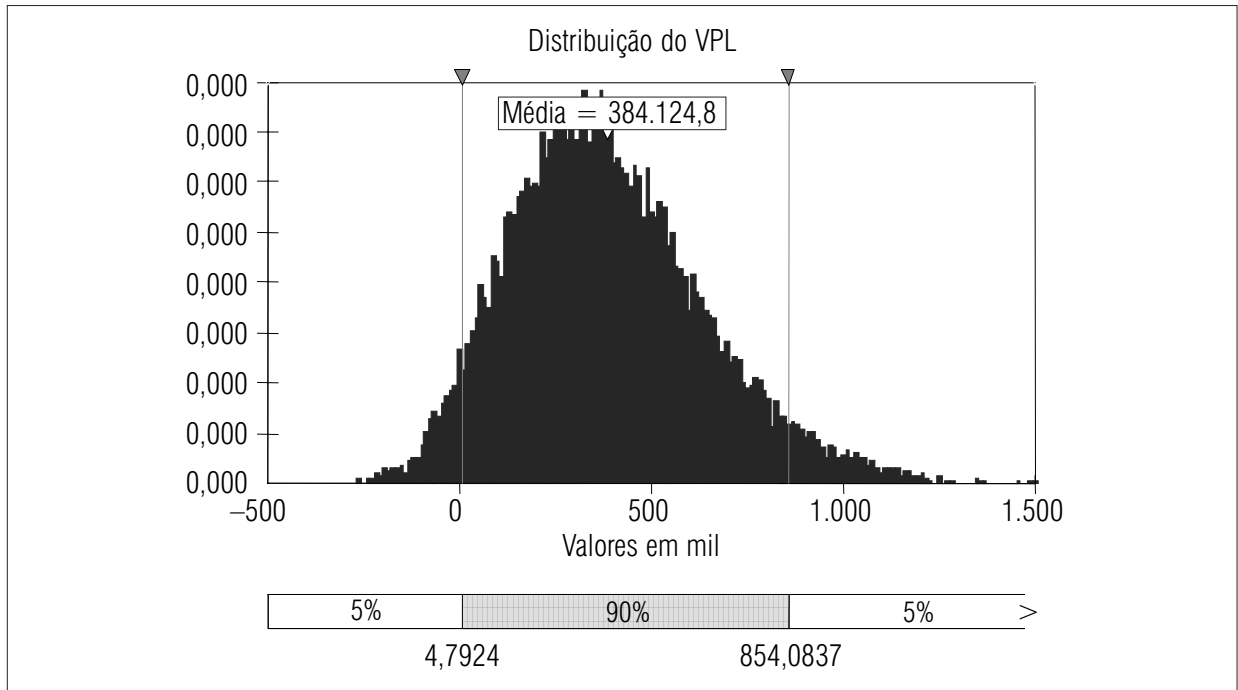

\section{Valoração das opções}

As opções de garantia serão exercidas sempre que a receita real em um determinado ano for menor do que a receita mínima preestabelecida no contrato de concessão. Para um prazo de concessão de 25 anos, essas garantias podem ser modeladas com uma série de 25 opções européias, com prazo de maturidade entre um e 25 anos. Dos parâmetros necessários para a completa definição do processo das receitas, falta apenas a determinação do prêmio de risco para a modelagem neutra a risco. Esse parâmetro é obtido endogenamente por meio da taxa esperada de retorno para o projeto e da volatilidade dos fluxos de caixa.

A simulação do fluxo de caixa estocástico do projeto realizado conforme proposto por $\mathrm{BDH}$ (2005) indica que a volatilidade dos fluxos de caixa é de $24,4 \% .^{3}$ Assumindo uma taxa livre de risco de $7 \%$ a.a., o prêmio de risco dos fluxos de caixa é dado por $\mu-r=\beta_{C}\left(E\left[R_{m}\right]-r\right)=8 \%$, e pela equação (3)

\footnotetext{
${ }^{3}$ A premissa de que o processo estocástico do projeto é um MGB implica que a volatilidade é constante ao longo da vida útil da concessão. O modelo proposto pode ser estendido facilmente para incorporar casos de volatilidade não constante.
} 
obtemos $\lambda \sigma_{R}=0,08 \frac{0,06}{0,244}=0,02$. Isso implica que o prêmio de risco das receitas pode ser determinado pelo prêmio de risco e da volatilidade do projeto, ou do seu fluxo de caixa. Dado o processo neutro a risco das receitas definido em (2) e o valor do exercício em cada ano, considerando uma receita mínima equivalente a $70 \%$ do seu valor esperado, o valor da opção é determinado por simulação. Levando-se em conta que os custos operacionais independem do nível da receita, o valor do projeto aumenta do valor agregado de todas as opções deduzido o valor dos impostos devidos.

$$
\text { Garantia }=\sum_{i=1}^{n} \text { Opçãa } i(1-T)
$$

onde $T$ representa os impostos devidos.

O efeito das garantias de receita ao nível de $70 \%$ se reflete num aumento líquido no valor do projeto de $\mathrm{R} \$ 219,8$ milhões, por meio de uma complementação de receita que ocorrerá sempre que o valor observado for menor do que $o$ piso preestabelecido. Outra vantagem importante da garantia de receita é a significativa melhora na distribuição de risco do projeto devido à eliminação da probabilidade de ocorrência de situações desfavoráveis extremas, já que essa garantia tem o efeito de um seguro. O resultado é que as possibilidades de ocorrerem resultados muito desfavoráveis são eliminadas, sem prejuízo da probabilidade de haver resultados melhores. Na figura 4 podemos observar o impacto da garantia de tráfego de $70 \%$ na redução de risco do projeto, onde fica clara a mudança do perfil da distribuição de risco da concessão.

\section{Figura 4}

\section{Distribuição do VPL da concessão com garantia de tráfego de $70 \%$}

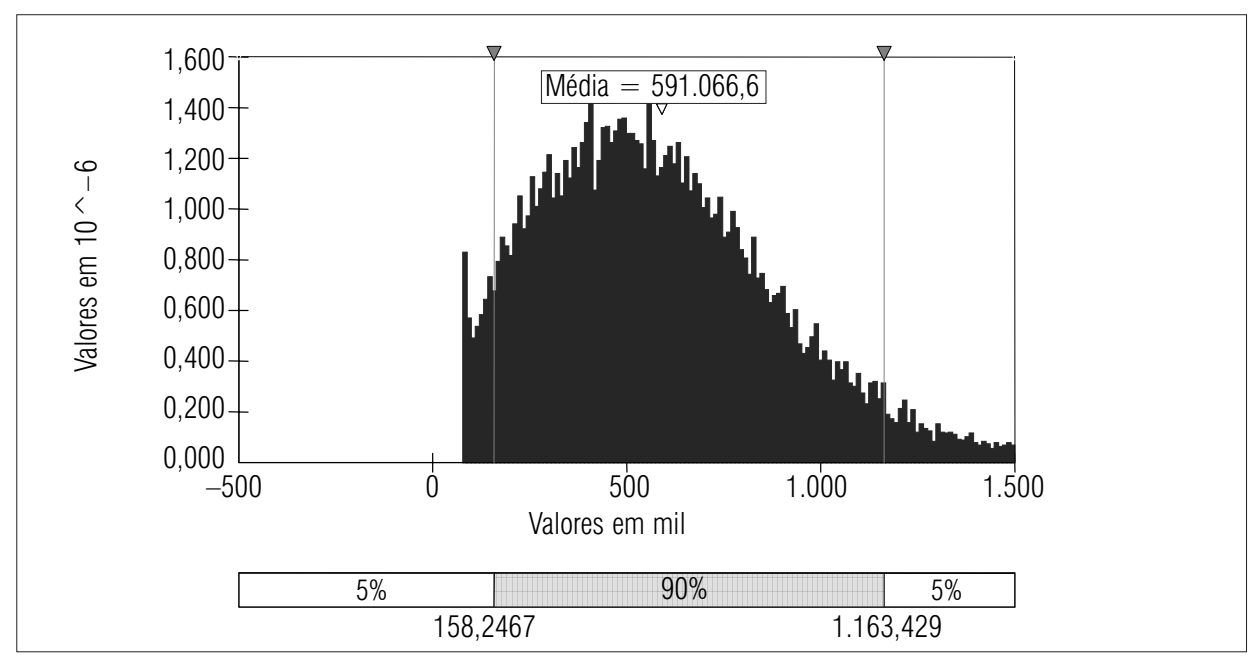


Outros níveis de garantia terão impactos distintos sobre o valor e risco do projeto, e na figura 5 podemos observar como esse aumento de valor ocorre à medida que o nível mínimo de garantia de tráfego aumenta. Uma garantia de $80 \%$, por exemplo, praticamente dobra o VPL da concessão ao mesmo tempo em que reduz consideravelmente o seu risco.

\section{Figura 5}

Valor do projeto em função do nível de garantia

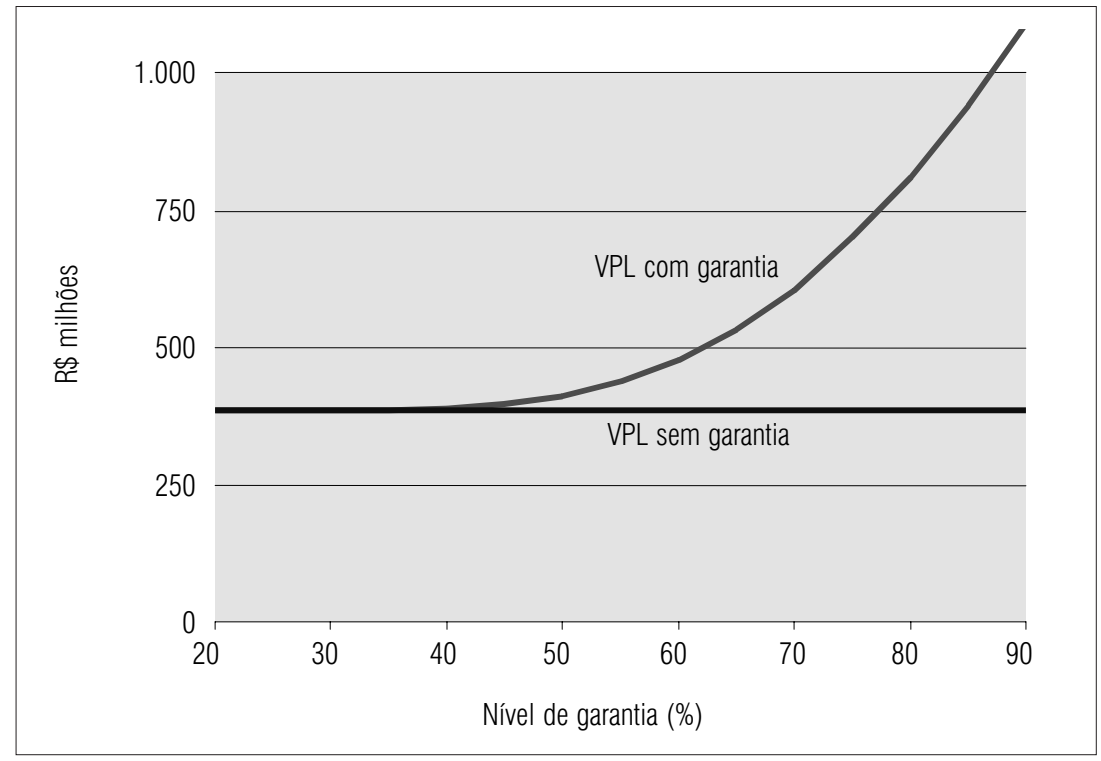

\section{Valor dos pagamentos esperados}

O valor esperado dos pagamentos a serem realizados em cada ano pelo governo para honrar as garantias contratuais de receita mínima pode ser estimado modelando-se o processo estocástico verdadeiro das receitas definido em erro! A origem da referência não foi encontrada. E aplicando-se a regra de decisão da equação (1). Note que, diferente do modelo utilizado para avaliação do valor da garantia para o concessionário, para a determinação da probabilidade de ocorrência dos pagamentos futuros e o seu valor, é necessário adotar o processo verdadeiro da evolução das receitas, uma vez que a opção será exercida sobre o seu valor real. Por meio de uma simulação com 10 mil iterações é calculado o valor da garantia em cada ano e cada iteração. O gráfico da figu- 
ra 6 apresenta o valor dos pagamentos esperados em função do ano da concessão e do nível da garantia oferecida. Podemos observar que o valor dos pagamentos esperados é praticamente nulo para valores de garantia abaixo de 50\%, e cresce com o número de períodos e com o aumento do valor da garantia. Isso significa que os maiores pagamentos esperados tendem a ocorrer nos anos finais da concessão.

\section{Figura 6}

\section{Valor esperado dos pagamentos futuros}

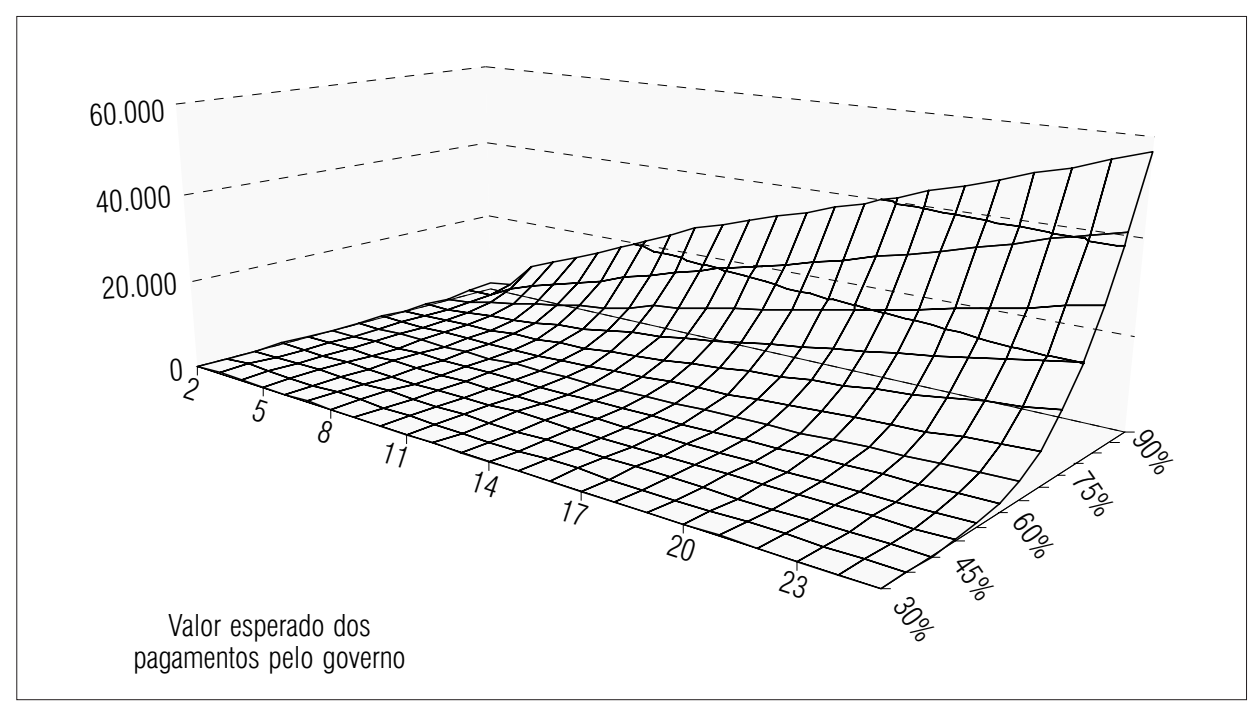

Para efeito de ilustração, analisamos que, com mais detalhes, o pagamento esperado para um nível de garantia e ano específicos corresponde a apenas um dos nós da malha da figura 6. A distribuição de probabilidades do pagamento esperado para o ano 10 da concessão, considerando um nível de garantia de receita de $70 \%$, é apresentada na figura 7 . O seu valor esperado é de $\mathrm{R} \$ 2,1$ milhões, com uma probabilidade de $93,7 \%$ do pagamento ser zero.

Embora o valor esperado seja pequeno em relação ao volume do projeto, pagamentos significativamente maiores são passíveis de ocorrer, embora com probabilidade muito pequena, como podemos ver na distribuição cumulativa da figura 8 (95\% de probabilidade de ser menor do que $\mathrm{R} \$ 10$ milhões e 99\% de ser menor que R\$ 60 milhões). 
Figura 7

Distribuição do pagamento no ano 10

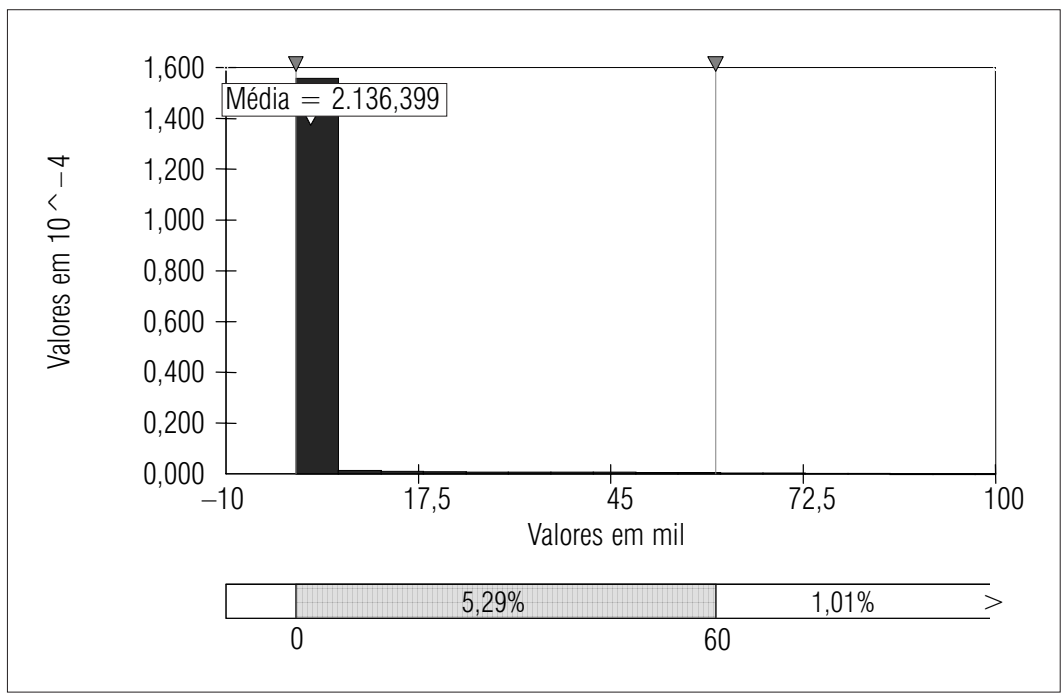

Figura 8

Distribuição do pagamento no ano 10

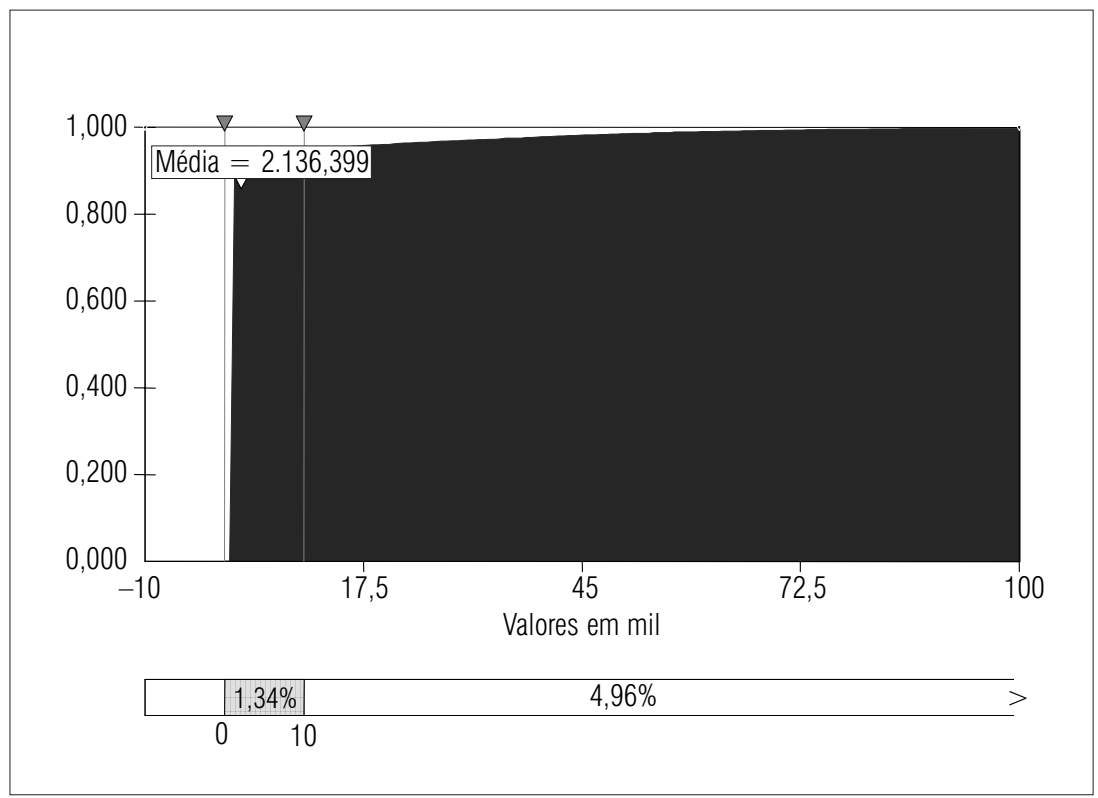




\section{Custo das garantias}

Já que determinamos o valor esperado e a probabilidade de incorrer num pagamento no futuro, qual seria o valor presente do custo desses pagamentos futuros? Intuitivamente podemos pensar em simplesmente obter o valor presente descontando desses pagamentos futuros a taxa livre de risco. Infelizmente, nesse caso, estaríamos ignorando o risco dos pagamentos futuros, pois o nível de tráfego, e, conseqüentemente, as receitas do projeto são correlacionados com o mercado e, portanto, sujeitas a risco sistemático. Dessa forma, o risco para o governo é real no sentido em que uma redução do nível de atividade econômica no mercado afetará negativamente as receitas da concessão, fazendo com que o governo seja obrigado a honrar garantias, no momento em que suas receitas de impostos também se reduziram. Uma análise que não leve isso em conta subestimará o custo dessas garantias. Devido ao princípio da não-arbitragem, sabemos que o valor de mercado das garantias de receita para o governo deve necessariamente ser igual ao valor para o concessionário, já calculado anteriormente. Por outro lado, essa análise simplificada pode fornecer alguma indicação dos custos para o governo, se considerarmos que a correlação dos pagamentos devidos com o valor dos demais ativos e passivos do governo é fraca. Isso poderia ocorrer, por exemplo, se considerarmos que o tráfego rodoviário é mais fortemente correlacionado com o PIB da região que ele serve do que com o PIB agregado do país, considerando-se a diversidade dos níveis de desenvolvimento e crescimento das regiões do Brasil. Nesse caso, uma redução no preço internacional da soja que reduza o tráfego na BR-163, por exemplo, poderia ser compensada por um aumento de demanda em outra região, como as exportações de minério de ferro de Carajás. Nesse caso, a receita do governo não seria afetada por um menor tráfego na rodovia.

Desconsiderando os riscos associados ao pagamento das garantias, obtemos valores significativamente menores para o custo total esperado das garantias de receita para esse projeto. Os custos dos diferentes níveis de garantias estão ilustrados na figura 9, onde podemos ver uma comparação do valor da garantia para o concessionário com o seu custo para o governo, considerandose que as receitas do governo não têm nenhuma correlação com os riscos do projeto. 
Figura 9

\section{Custo para governo desconsiderando risco}

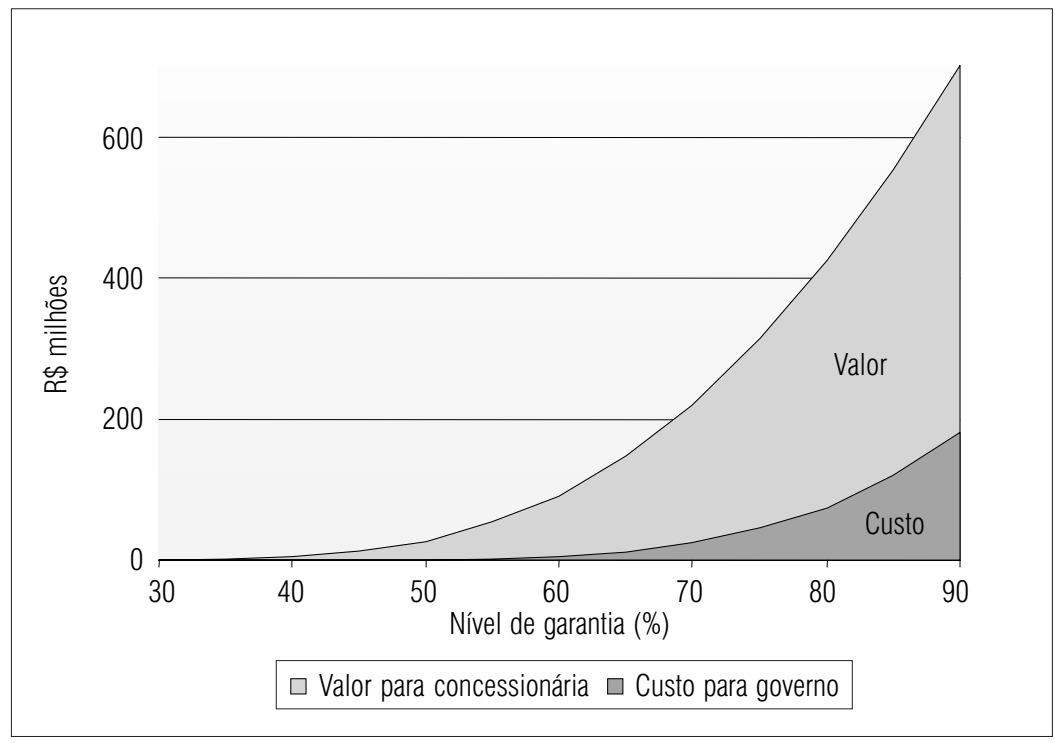

Figura 10

Distribuição do custo da garantia

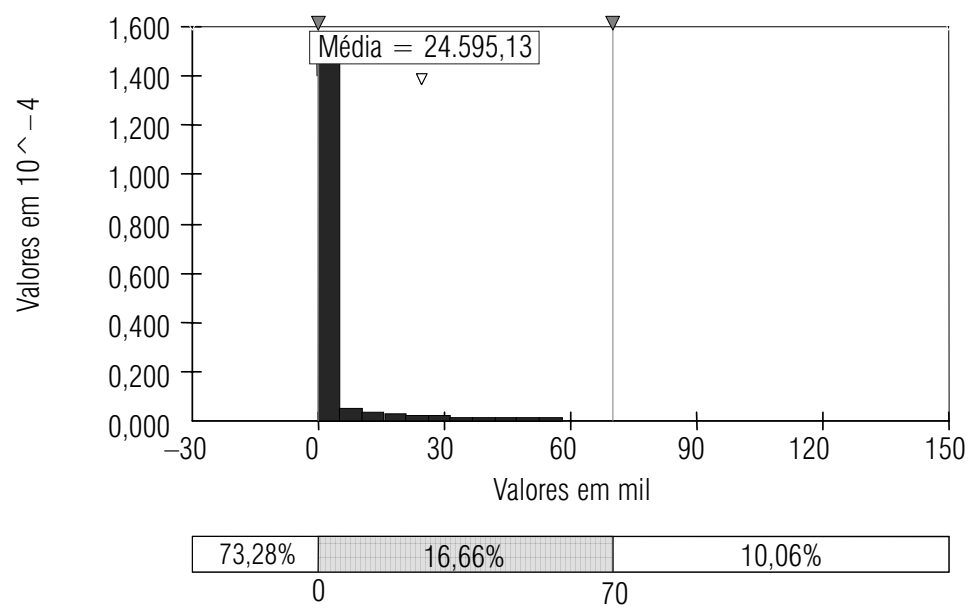


Levando-se em conta um nível hipotético de garantia de receita de 70\%, o valor esperado do pagamento total para esse nível de garantia é de $\mathrm{R} \$ 24,5$ milhões. A figura 10 mostra que existe uma probabilidade de $73,3 \%$ do custo ser zero, $80,36 \%$ de ser menor que $\mathrm{R} \$ 10$ milhões para o governo e de $90 \%$ de ser menor do que aproximadamente $\mathrm{R} \$ 71$ milhões.

\section{Conclusões}

Dado que o estoque de ativos privatizáveis do Estado se reduziu devido à venda de empresas estatais ocorrida na década de 1990, os próximos projetos de investimento privado em infra-estrutura pública tendem a ser projetos pioneiros. Neste artigo apresentamos uma análise do problema do investimento privado em projetos de infra-estrutura pública e concluímos que para algumas classes de projetos, pode ser necessário que os riscos sejam repartidos também pelo governo por meio de garantias contratuais. Uma das formas que essas garantias podem tomar é a de estabelecer um piso de receita, abaixo do qual o concessionário recebe um subsídio governamental, e mostramos que garantias de receita podem ser uma alternativa econômica para viabilizar projetos de infra-estrutura pública, onde os riscos são tais que não atraem os investidores privados. Por outro lado, a determinação do nível ótimo de risco é de fundamental importância para evitar que essas garantias sejam dadas em excesso ou que sejam insuficientes, e propusemos uma modelagem matemática que permite determinar o valor agregado ao projeto pela garantia governamental por meio de uma análise quantitativa para diversos níveis de suporte.

A metodologia proposta neste artigo pode ser utilizada pelo governo para avaliar as garantias a serem oferecidas em projetos de PPP, e pode, ainda, permitir que se calibre o nível de garantia ótimo em função do grau de redução de risco desejado. Para as PPPs que estão em estudo pelo governo federal e pelos governos estaduais, a aplicação desta metodologia pode auxiliar na indicação da melhor alternativa de modelagem contratual para o poder público. Para o governo, a concessão de garantias pode servir para alavancar a sua capacidade de investimento, redirecionando os seus recursos do financiamento de obras públicas para a constituição de uma reserva técnica das garantias, contanto que sejam tomados os cuidados necessários na seleção dos projetos que irão compor o seu portfólio de PPPs.

Apesar de termos analisado apenas o caso de um piso de receita, o modelo apresentado é flexível o suficiente para lidar também com um teto de receita, bem como outras formas de garantia como, por exemplo, a adoção de um modelo de prazo de concessão variável (LPVR) conforme sugerido por Engel, Fisher, Galetovic (2000). 


\section{Referências bibliográficas}

BEATO, P. Road concessions: lessons learned from the experience of four countries. Infrastructure and financial markets division of the sustainable development department. Inter-American Development Bank, 1997.

BLACK, F; SCHOLES, M. The pricing of options and corporate liabilities. Journal of Political Economy, n. 81, p. 637-659, 1973.

BOWE, Michael; LEE, Ding. Project evaluation in the presence of multiple embedded real options: evidence from the Taiwan High-Speed Rail Project. Journal of Asian Economics, n. 15, p. 71-98, 2004.

BRANDÃO, L. Uma aplicação da teoria das opções reais em tempo discreto para a valoração de uma concessão rodoviária. 2002. Tese (Doutorado) — PUC, Rio de Janeiro.

.; DYER, J.; HAHN, W. Response to comments on Brandão et al. Decision Analysis, v. 2, n. 2, p. 103-109, June 2005.

CHAROENPORNPATTANA S.; MINATO T.; NAKAHAMA S. Government supports as bundle of real options in built-operate-transfer highways projects. 2002. Dissertação (Mestrado) The University of Tokyo.

COPELAND, T.; ANTIKAROV, V. Real options. New York: Texere LLC, 2001.

CROCKER, K.; MASTEN, S. Regulation and administered contracts revisited: lessons from transaction-cost economics for public utility regulation. Journal of Regulatory Economics, n. 9, p. 5-40, 1996.

DAILAMI, M.; KLEIN, M. Government support to private infrastructure projects in emerging markets. In: IRWIN, T. et al. (Eds.). Dealing with public risk in private infrastructure, p. 2142. Washington DC: The World Bank, 1997.

ENGEL, E.; FISHER, R.; GALETOVIC, A. The Chilean infraestructure concessions program: evaluation, lessons and prospects for the future. Chile: Centro de Economia Aplicada (CEA), Departamento de Ingenieria Industrial de Chile, 2000. (Working paper).

FISHBEIN, G.; BABBAR, S. Private financing of toll roads. Washington DC: The World Bank, 1996. (RMC Discussion Paper Series 117.)

GÓMEZ-IBÁNEZ, J. A. Mexico's private toll road program. Kennedy School of Government Case Program: case C15-97-1402.0. Harvard, 1997.

GROSSMAN, S.; HART, O. The costs and benefits of ownerships: a theory of vertical and lateral integration. Journal of Political Economy, n. 94, p. 691-719, 1986.

HART, O.; MOORE, J. Property rights and the nature of the firm. Journal of Political Economy, n. 9, p. 1119-1158, 1990. 
HULL, J. Options, futures and other derivatives. New Jersey: Prentice Hall, 2003.

IRWIN, T. et al. Managing government exposure to private infrastructure risks. The World Research Observer, Washington, DC: IBRD, World Bank, v. 14, n. 2, p. 229-245. Aug. 1999.

. Public Money for private infrastructure: deciding when to offer guarantees, outputbased subsidies, and other fiscal support. Washington, DC: The World Bank, July 2003. (World Bank Working paper n. 10.)

KEKERI, S.; KOLO, A. F. Privatization: trends and recent developments. 2005. (World Bank Policy Research Paper), n. 3.735. Disponível em: <http://econ.worldbank.org>.

KLEIN, B.; CRAWFORD, R.; ALCHIAN, A. Vertical integration, appropriable rents, and the competitive contracting process. Journal of Law and Economics, n. 21, p. 297-326, 1978.

LEWIS, C.; MODY, A. Risk management systems infrastructure liabilities. In: IRWIN, Timothy et al. (Eds.). Dealing with public risk in private infrastructure. Washington, DC: World Bank, 1998.

NG, F. G.; BJÖRNSSON, H. C. Using real option and decision analysis to evaluate investments in the architecture, construction and engineering industry. Construction Management and Economics, n. 22, p. 471-482, June 2004.

ROSE, S. Valuation of interacting real options in a toll road infrastructure project. The Quarterly Review of Economics and Finance, v. 38, p. 711-723, 1998. (special issue.)

THOBANI, Mateen. Private infrastructure, public risk. Finance and Development, International Monetary Fund, Mar. 1999.

TRAFFIC forecasting risk: study update 2003. Standard and Poor's Infrastructure Finance, Nov. 2003.

TRAFFIC risk in start-up toll facility. Standard and Poor's Infrastructure Finance, 2002.

WILLIAMSON, O. Markets and hierarchies - analysis and antitrust implications: a study of the economics of internal organization. New York: The Free Press, 1975a.

. The economic institutions of capitalism: firms, markets, relational contracting. New York: The Free Press, 1975b.

. Transaction-cost economics: the governance of contractual relationships. Journal of Law and Economics, n. 22, p. 233-261, 1979. 


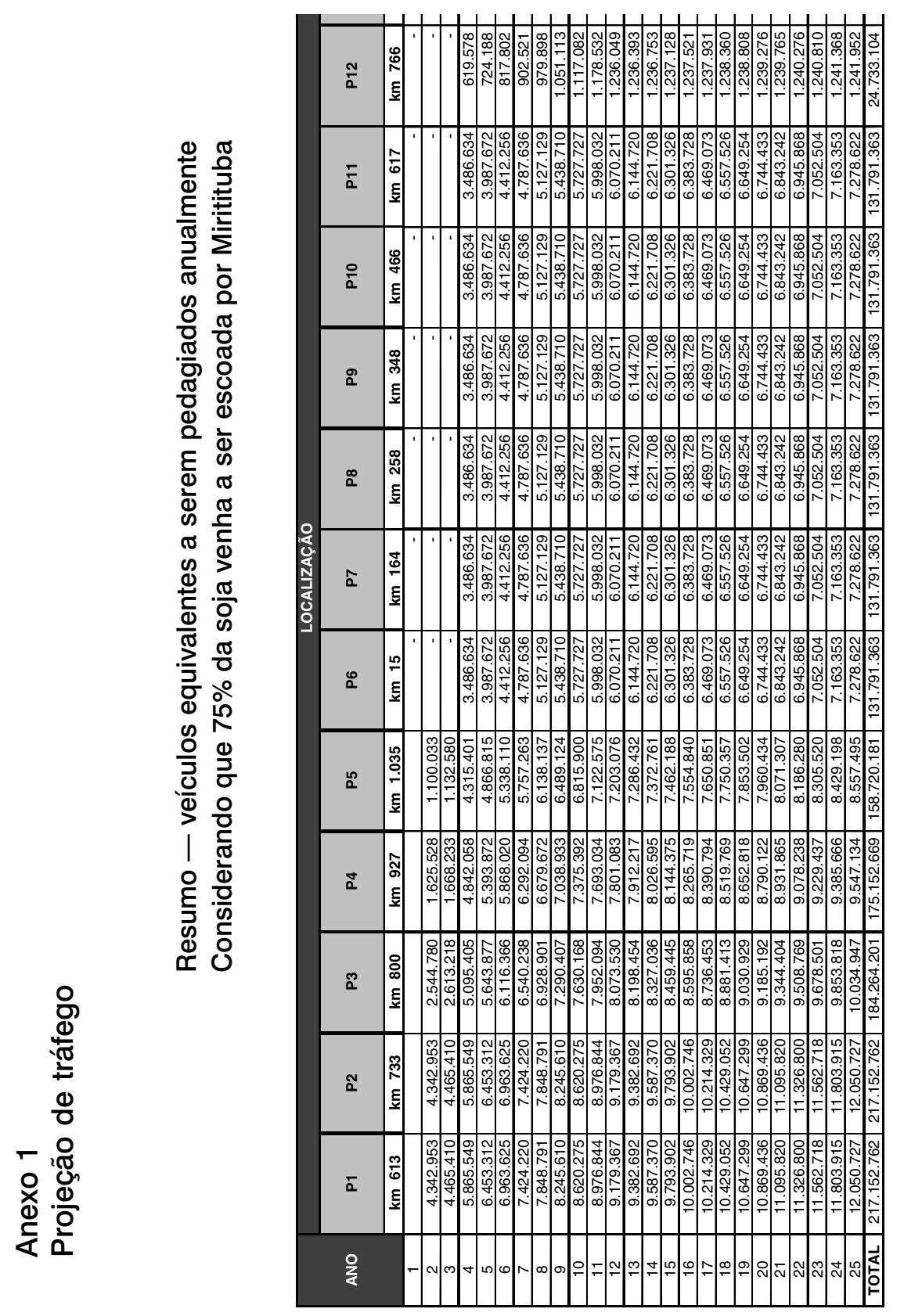

RaP Rio de Janeiro 4l(b):1035-67, Nov./Dez. 2007 


\section{Anexo 2}

\section{Investimentos e custos operacionais}

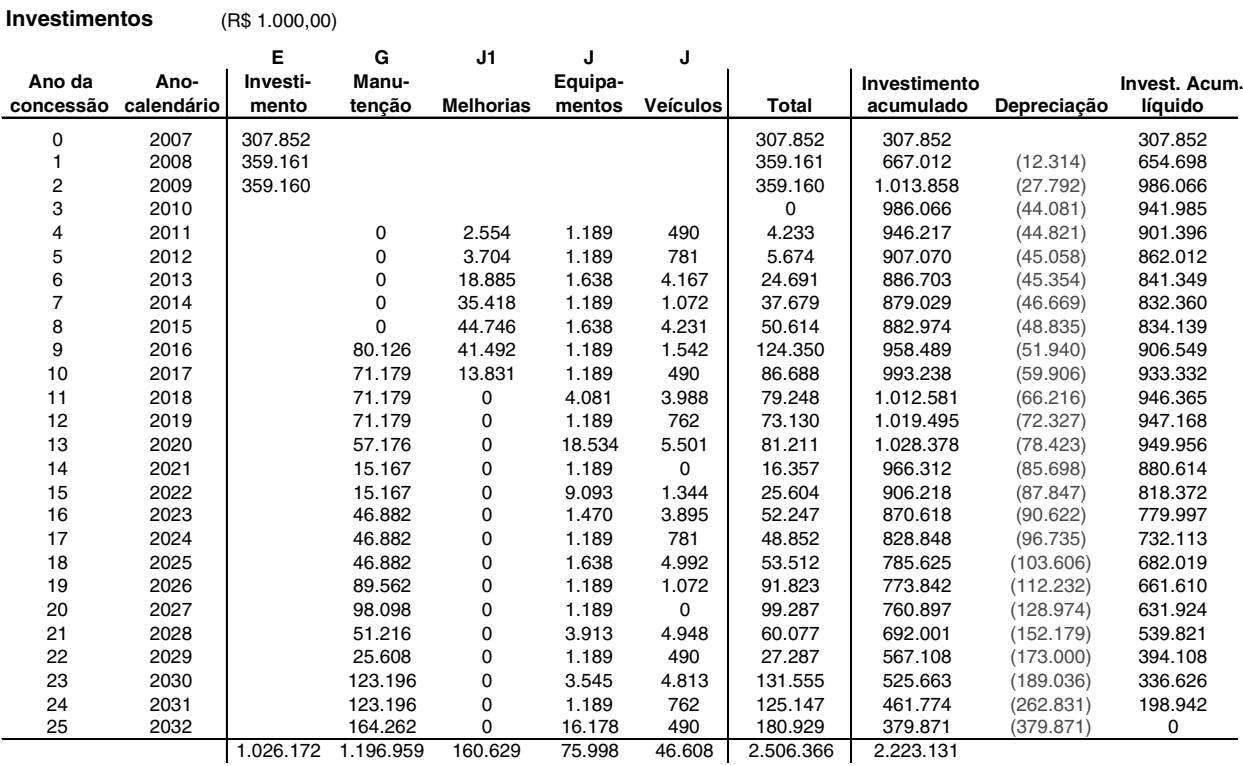

\begin{tabular}{|c|c|c|c|c|c|c|c|}
\hline \multicolumn{2}{|c|}{ Custos Operacionais } & \multicolumn{3}{|c|}{$(\mathrm{R} \$ 1.000,00)$} & \multirow[b]{2}{*}{$\begin{array}{c}\text { J-Custos } \\
\text { Serviços } \\
\text { terceirizados }\end{array}$} & \multirow[b]{2}{*}{$\begin{array}{l}\text { J-Custos } \\
\text { Seguros }\end{array}$} & \multirow[b]{2}{*}{$\begin{array}{l}\text { Total custos } \\
\text { operacionais }\end{array}$} \\
\hline $\begin{array}{c}\text { Ano da } \\
\text { concessão }\end{array}$ & $\begin{array}{c}\text { Ano- } \\
\text { calendário }\end{array}$ & $\begin{array}{l}\text { J-Custos } \\
\text { Conser- } \\
\text { vação }\end{array}$ & $\begin{array}{c}\text { J-Custos } \\
\text { Salários e } \\
\text { encargos }\end{array}$ & $\begin{array}{l}\text { Desp. } \\
\text { G\&A }\end{array}$ & & & \\
\hline 0 & 2007 & & & & & & \\
\hline 1 & 2008 & 0 & 0 & 0 & 0 & 0 & 0 \\
\hline 2 & 2009 & 8.566 & 15.689 & 5.570 & 1.080 & 8.137 & 39.042 \\
\hline 3 & 2010 & 8.593 & 15.689 & 6.234 & 1.080 & 8.077 & 39.673 \\
\hline 4 & 2011 & 14.644 & 33.032 & 11.146 & 1.080 & 7.857 & 67.758 \\
\hline 5 & 2012 & 19.015 & 33.032 & 11.146 & 1.080 & 7.610 & 71.882 \\
\hline 6 & 2013 & 23.369 & 33.032 & 11.146 & 1.080 & 7.338 & 75.964 \\
\hline 7 & 2014 & 23.369 & 33.032 & 11.146 & 1.080 & 7.045 & 75.672 \\
\hline 8 & 2015 & 23.369 & 33.032 & 11.146 & 1.080 & 6.734 & 75.360 \\
\hline 9 & 2016 & 23.369 & 33.032 & 11.146 & 1.080 & 6.404 & 75.030 \\
\hline 10 & 2017 & 23.369 & 33.032 & 11.146 & 1.080 & 6.058 & 74.684 \\
\hline 11 & 2018 & 23.369 & 33.032 & 11.146 & 1.080 & 5.696 & 74.322 \\
\hline 12 & 2019 & 23.369 & 33.032 & 11.146 & 1.080 & 5.329 & 73.955 \\
\hline 13 & 2020 & 23.369 & 33.032 & 11.146 & 1.080 & 4.956 & 73.583 \\
\hline 14 & 2021 & 23.369 & 33.032 & 11.146 & 1.080 & 4.578 & 73.204 \\
\hline 15 & 2022 & 23.369 & 33.032 & 11.146 & 1.080 & 4.194 & 72.821 \\
\hline 16 & 2023 & 23.369 & 33.032 & 11.146 & 1.080 & 3.804 & 72.431 \\
\hline 17 & 2024 & 23.369 & 33.032 & 11.146 & 1.080 & 3.409 & 72.035 \\
\hline 18 & 2025 & 23.369 & 33.032 & 11.146 & 1.080 & 3.006 & 71.633 \\
\hline 19 & 2026 & 23.369 & 33.032 & 11.146 & 1.080 & 2.598 & 71.224 \\
\hline 20 & 2027 & 23.369 & 33.032 & 11.146 & 1.080 & 2.183 & 70.809 \\
\hline 21 & 2028 & 23.369 & 33.032 & 11.146 & 1.080 & 1.761 & 70.387 \\
\hline 22 & 2029 & 23.369 & 33.032 & 11.146 & 1.080 & 1.332 & 69.958 \\
\hline 23 & 2030 & 23.369 & 33.032 & 11.146 & 1.080 & 895 & 69.522 \\
\hline 24 & 2031 & 23.369 & 33.032 & 11.146 & 1.080 & 452 & 69.078 \\
\hline 25 & 2032 & 23.369 & 33.032 & 11.146 & 1.080 & 8.647 & 77.274 \\
\hline & & 518.197 & 758.074 & 257.010 & 25.920 & 118.101 & 1.677 .302 \\
\hline
\end{tabular}




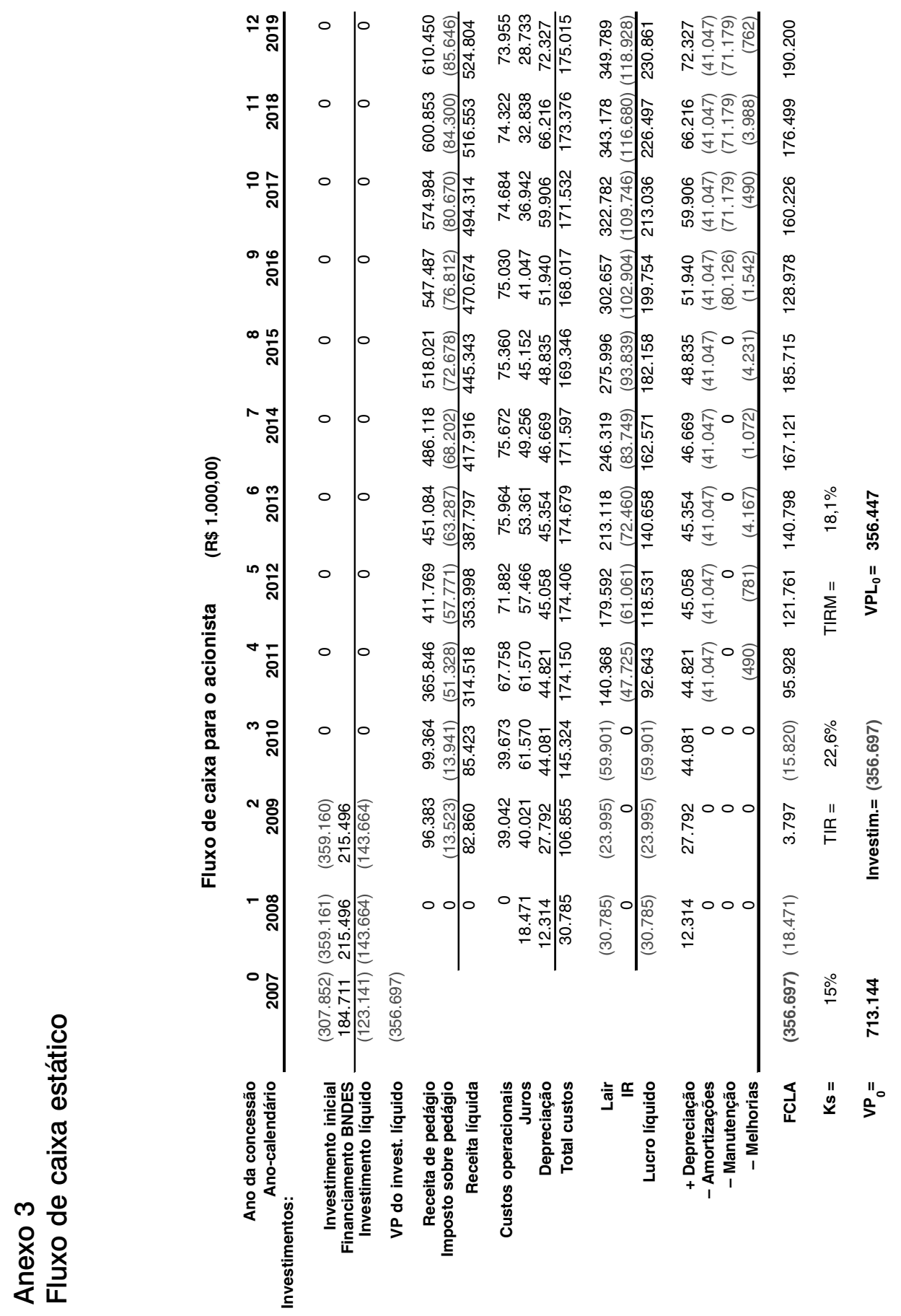




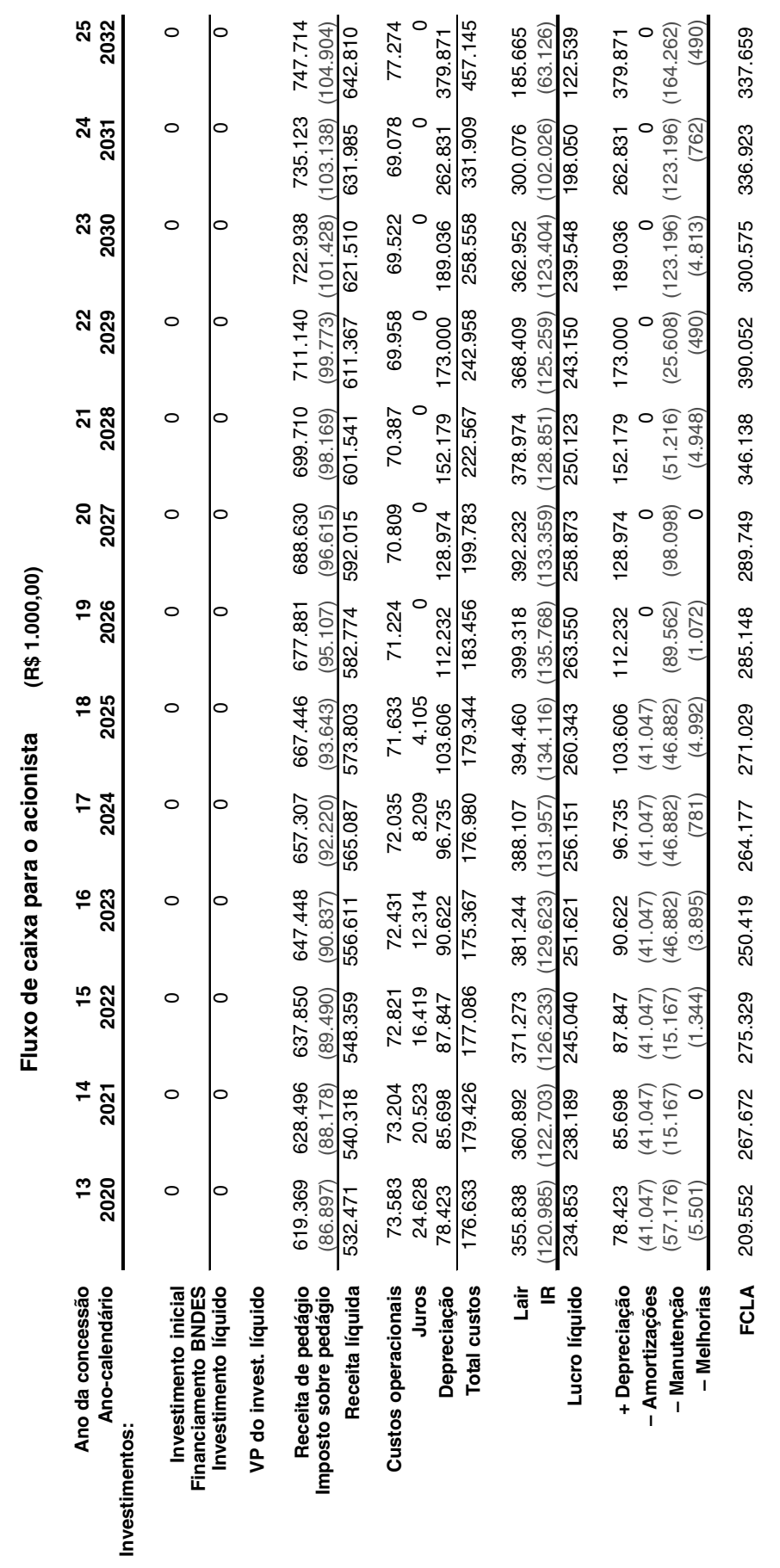

